Available online at GSC Online Press Directory

GSC Biological and Pharmaceutical Sciences

e-ISSN: 2581-3250, CODEN (USA): GBPSC2

Journal homepage: https://www.gsconlinepress.com/journals/gscbps

(RESEARCH ARTICLE)

\title{
Dihydroquercetin (taxifolin) attenuates dexamethasone activity on prostaglandin E- 2 but potentiates thromboxane-A2 action in gastric acid secretion in wistar rats
}

\author{
Etah Etah Nkanu* \\ Department of Physiology, Faculty of Basic Medical Sciences, Cross River University of Technology, Calabar, Okuku \\ Campus, Yala, Nigeria.
}

Publication history: Received on 15 November 2020; revised on 22 December 2020; accepted on 24 December 2020

Article DOI: https://doi.org/10.30574/gscbps.2020.13.3.0374

\begin{abstract}
The activity of dexamethasone and taxifolin \{(2R, 3R)-2-(3, 4-Dihydroxyphenyl)-3,5,7-trihydroxy-2,3-dihydrochromen4-one supplementation on prostaglandin E2 and thromboxane A2 in gastric acid secretion and anti-ulcer was studied. Twenty male Wistar rats (180g-200g body weight) were used. The rats were randomly selected into four groups containing 5 rats each. Group 1 was the control group fed on normal rat feed. Group 2 received $3 \mathrm{mg} / \mathrm{kg}$ of Dexamethasone (intraperitoneally) at one day interval. Group 3 received $3 \mathrm{mg} / \mathrm{kg}$ of Dex. intraperitoneally and $1 \mathrm{mg} / \mathrm{kg}$ body weight of taxifolin orally while group 4 received $1 \mathrm{mg} / \mathrm{kg}$ body weight of taxifolin. At the end of 6 weeks, basal and peak gastric acid output was measured by continuous perfusion of rats stomach under anaesthesia with normal saline at the rate of $1 \mathrm{ml} / \mathrm{min}$. Gastric acid, mucus secretion, ulcer index, PGE-2 and thromboxane A2 activity were determined according to standard procedures. Results showed a significantly $(\mathrm{p}<.05)$ decreased prostaglandin and mucus secretion level and a raised thromboxane concentrations and gastric acid output in dexamethasone administration. Taxifolin significantly $(\mathrm{p}<.05)$ lowered thromboxane A2 concentration in Dex treatment while increasing the prostaglandin E2 level. We conclude that Taxifolin decreases dexamethasone- induced gastric acid secretion, increases prostaglandin activity but reduces thromboxane concentration.
\end{abstract}

Keywords: Prostaglandin E2; Thromboxane A2; Taxifolin; Dexamethasone; Gastric acid

\section{Introduction}

Dexamethasone is a synthetic glucocorticoid that appears to have a double face effect. Its activity in man and experimental animals has generated a long standing debate on whether treatment with glucocorticoids leads to peptic ulcer or not [1,2] Available reports have shown that the use of glucocorticoids (dexamethasone) could be gastroprotective under physiologic conditions [3] on one hand, and on the other hand, could be causal to many disease states such as hypertension associated with increased oxidative stress and excess production of reactive oxygen species (ROS) often generated by nicotinamide adenine dinucleotide phosphate-oxidase (NAPDH) [4] and contributing to tissue damage, nitric oxide (NO) deficiency and endothelial dysfunction ([5], hormonal changes in the reproductive system and ulceration in the gastric mucosa. For example, various works have demonstrated that the administration of glucocorticoids to animals can attenuate gastric mucosal erosion formation $[6,7,8]$. Similarly, It has also been shown that pretreatment with dexamethasone $[6,7]$ may protect the stomach from ethanol or non-steroidal anti-inflammatory drugs (NSAID)-induced injury, respectively thereby maintaining the gastric mucosal integrity $[9,10]$.

\footnotetext{
${ }^{*}$ Corresponding author: Etah Etah Nkanu

Department of Physiology, Faculty of Basic Medical Sciences, Cross River University of Technology, Calabar, Okuku Campus, Yala, Nigeria.

Copyright $(2020$ Author(s) retain the copyright of this article. This article is published under the terms of the Creative Commons Attribution Liscense 4.0.
} 
Prostanoids including prostaglandins (PGE2) and prostaglandin-like substance such as thromboxane -A2 (THX-A2), with potent biological activity, either exogenous or endogenous have also been reported to be pivotal in maintaining the integrity of the mucosal wall [11]. They are found in high concentration in the gastric mucosa and gastric juice. Endogenous prostaglandins inhibit acid secretion, stimulate mucus and bicarbonate secretion, alter mucosal blood flow, and protect against acute mucosal damage [12]. Our concern in this work, is to find out the possible physiologic actions of dihydroquerceten (taxifolin) on dexamethasone induced gastric acid secretion and denudation of the mucosal epithelium.

\section{Material and methods}

\subsection{Experimental Design}

Twenty male Wistar rats (180g-200g body weight) were used. The rats were randomly selected into four groups containing 5 rats each. Group 1 was the control group fed on normal rat feed. Group 2 received $3 \mathrm{mg} / \mathrm{kg}$ of Dexamethasone (intraperitoneally) at one day interval. Group 3 received $3 \mathrm{mg} / \mathrm{kg}$ of Dex. intraperitoneally and $1 \mathrm{mg} / \mathrm{kg}$ body weight of taxifolin orally while group 4 received $1 \mathrm{mg} / \mathrm{kg}$ body weight ot taxifolin. At the end of 6 weeks, basal and peak gastric acid output was measured by continuous perfusion of rat's stomach under anaesthesia with normal saline at the rate of $1 \mathrm{ml} / \mathrm{min}$. Basal gastric acid secretion and maximal (Histamine -induced), prostaglandin E2 and thromboxane A2 activity were determined according to standard procedures. Ethical approval for the study was obtained from the Faculty of Basic Medical Science Animal Research Ethical Committee of Cross River University of Technology, Calabar, Nigeria. The research work involved the use of experimental animals-Wistar rats (approval number FBMS/CRUTECH/18/020).

\subsection{Preparation of animals for collection of gastric acid}

Prior to the collection of gastric acid, animals were fasted for 12-18 hours in order to get rid of all fecal matter in the stomach. When animals were ready, they were anaesthesized intra-peritoneally using $25 \%$ urethane at a dose of $6 \mathrm{ml}$ per Kg body weight of the animal. The animals were laid in a dissecting board, and the traechea cannulated for proper aeration. Incision was also made along the the linea alba to expose the stomach. A thread was passed at the pyloric end under the pyloric sphincter. Also, an incision on the duodenum was made near the pyloric sphincter, cannulated and firmly tied.

An orogastric infusion tube was carefully passed through the oesophagus to the stomach and ligated just behind the tracheal cannula to prevent reflux. The exposed end of the orogastric tube was passed through a water bath to maintain the perfusate at $37^{\circ} \mathrm{C}$ and to pre warm the experimental solution. The other end of the orogastric tube was attached to a $50 \mathrm{ml}$ syringe mounted on a perfusor pump. The animal was warmed with a table lamp to maintain the body temperature at $37{ }^{\circ} \mathrm{C}$ and temperature monitored.

\subsection{Measurement of gastric acid output}

The method of [13] modified by [14] was used. The rats were first perfused with $0.9 \%$ normal saline at the rate of $0.1 \mathrm{ml} / \mathrm{min}$. The aliquots were collected after 10 minutes of infusion and were titrated with $0.01 \mathrm{~N} \mathrm{NaOH}$ using phenolphthalein as an indicator. Change in colour from colourless to pink indicated the end point of the titration and the volume of the base used was recorded. The first 10-20 minutes effluent collected was not used because of possible increase in acid secretion due to trauma. When a stable acid secretion was obtained, cimetidine $(11.40 \mathrm{mg} / \mathrm{kg}$ body weight,) was administered, followed by histamine (100mg/kg body weight,) and acid output determined every 10 minutes using the method described above.

\subsection{Cytoprotection study}

The cytoprotection experiment was done using the method of [15] $2 \mathrm{ml}$ of acid-alcohol (prepared from equal volumes of $0.1 \mathrm{~N} \mathrm{HCI}$ and $70 \%$ methanol) was introduced into the stomach of the rat through a duodenal incision with the help of a syringe and the pyloric-duodenal junction was ligated once again and left for 2 hours. The orogastric tap was reopened to flush, to get rid of any food materials. The ulcer score was then carried out after the method described by [15]. A magnifying lens and a vernier caliper were used to measure the extent of ulceration. 


\subsubsection{Determination of Ulcer Score}

- The ulcer scores were done as follows:

- Grade

- $0=$ No lesions

- $1=$ Haemorrhagic erosions (less than $5 \mathrm{~mm}$ ).

- $\quad 2=$ Haemorrhagic erosions (greater than $5 \mathrm{~mm}$ or small linear ulcers).

- $\quad 3=$ Many small linear ulcers (greater than $2 \mathrm{~mm}$ or small linear ulcer).

- $4=$ Multiple linear ulcers of marked size.

\subsection{Drug Treatment}

Drugs used in this study were cimetidine (Sigma, UK), and histamine (Sigma, UK),

\subsection{Determination of Thromboxane $A 2$ and PGE-2}

Thromboxane A2 and PGE2 were determined using the ELISA KIT/ manufacturers instruction.

\subsection{Statistical analysis}

All data obtained in this study were expressed as mean \pm standard error of mean. Collected data was analyzed using ANOVA (analysis of variance) using Graph Pad Prism version 5.0 for Windows (Graph Pad Software, San Diego, CA, USA). Bonferroni multiple comparison post hoc test was used to compare the level of significance between control and experimental groups. A value of $\mathrm{p}<0.05$ was considered significant.

\section{Results}

\subsection{Effects of dexamethasone and taxifolin on mucus secretion}

Mucus secretion was significantly $(\mathrm{p}<0.05)$ reduced in dexamethasone $(3 \mathrm{mg} / \mathrm{kg}$ body weight $)$ group when compared to control. There was also a significant $(\mathrm{p}<0.05)$ increase in gastric mucous secretion in the treatment groups compared to control and the Dex group (figure 6).

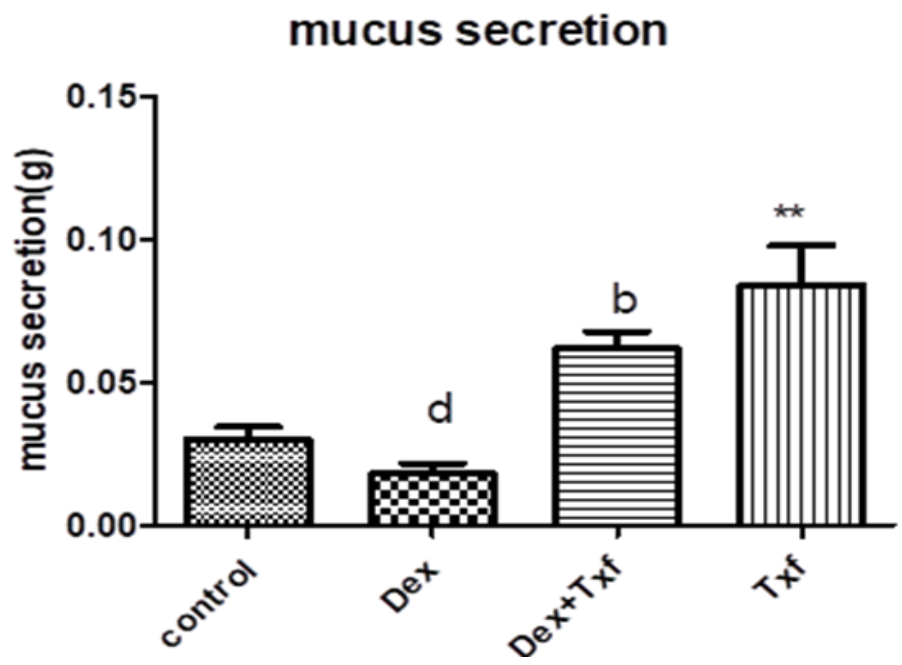

Figure 1. Showing effect dexamethasone and taxifolin treatment on mucus secretion in rats.

Values are expressed in mean $\pm \operatorname{SEM~} n=5, * *=p<0.01$ vs control;

\subsection{Effects of dexamethasone and taxifolin on gastric acid secretion}

Basal concentration of gastric acid output were significantly $(\mathrm{p}<0.05)$ lower in the treated groups. Gastric acid output following Histamine induced stimulation was significantly $(\mathrm{p}<0.01)$ lower in Dex group compared to control and other treatment groups (figure 2a). Similarly, the administration of cimetidine significantly $(\mathrm{p}<0.05)$ blocked gastric acid secretion in the treated group when compared to control (figure 2b) 


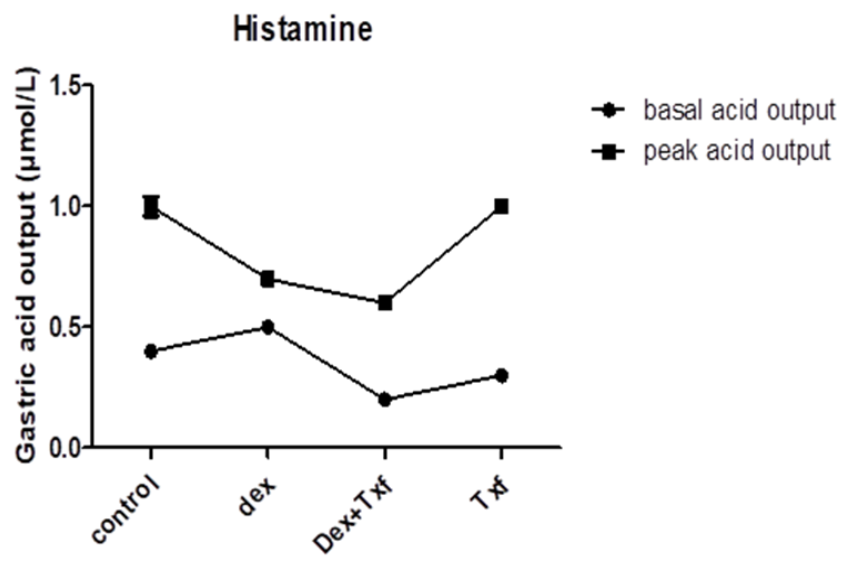

Figure 2a: showing effect of histamine introduction on gastric acid output in dexamethasone treated Wish rats and taxifolin supplementation. Values are expressed in Mens \pm SEM

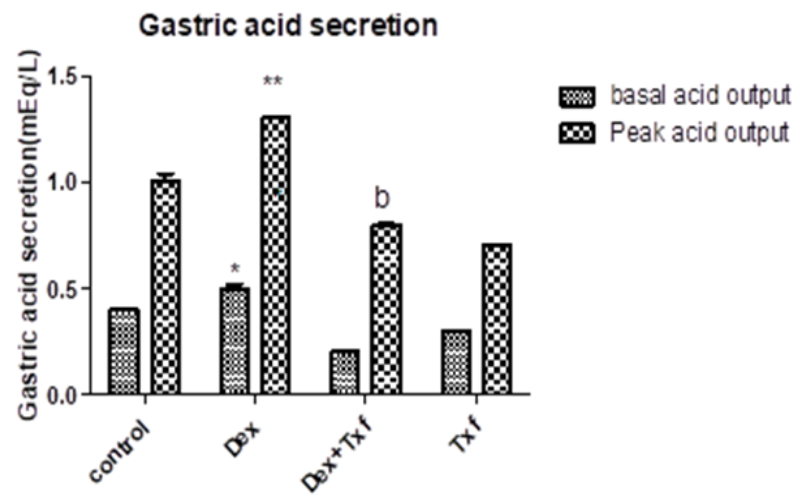

Figure 2b Showing effect of dexamethasone treatment and taxifolin (dihydroquercetin- $1 \mathrm{mg} / \mathrm{kg}$ ) supplementation on gastric acid secretion. Values are expressed in Mean \pm SEM; $n=5$.

\subsection{Effects of dexamethasone and taxifolin on prostaglandin E2 activity}

The serum concentration of prostaglandin E2 was significantly $(\mathrm{p}<0.01)$ reduced in dexamethasone treated rats (figure 5). Treatment with taxifolin significantly $(\mathrm{p}<0.01)$ increased PGE-2 concentration when compared to the Dexamethasone group.

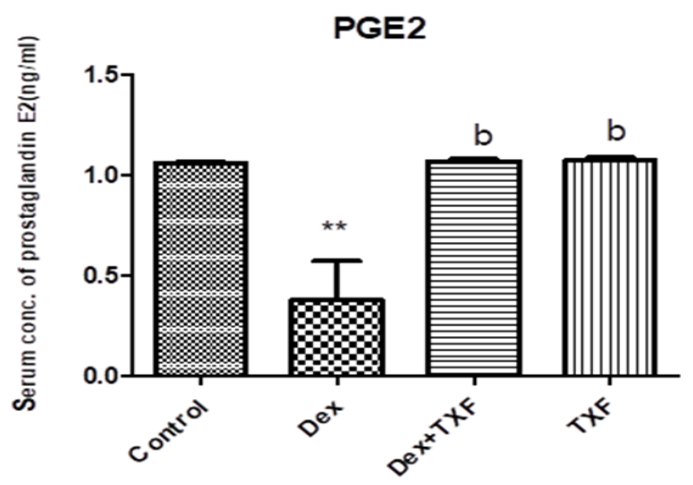

Figure 3. Showing effect of Taxifolin on prostaglandin E2 in dexamethasone treated rats.

Values are expressed in Mean \pm SEM $n=5^{* *}=p<0.001$ vs control $b=p<0,01$ vs De $x ; c=p<0.05$ vs TXF 


\subsection{Effects of dexamethasone and taxifolin on thromboxane $A 2$ concentration}

The serum concentration of thromboxane A2 was significantly $(\mathrm{p}<0.01)$ increased in dexamethasone treated rats. Treatment with taxifolin significantly $(\mathrm{p}<0.01)$ reduced Thromboxane A2 concentration when compared to the Dex.group (figure 4).

\section{Thromboxane A2}

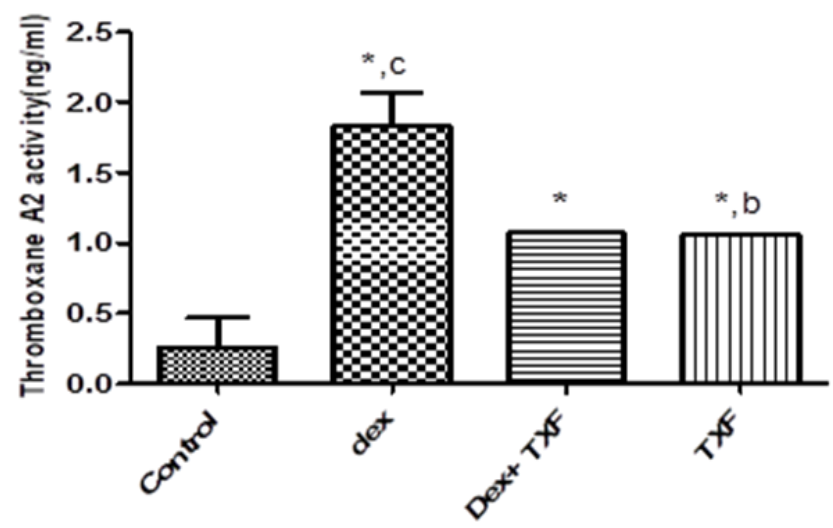

Figure 4 Showing effect of Taxifolin on Thromboxane A2 activity in dexamethasone treated rats. (Values are expressed in Mean \pm SEM $n=5^{*}=p<0.05$ vs control; $b=p<0.05$ vs Dex; $c=p<0.05$ vs TXF)

\subsection{Effects of dexamethasone and taxifolin on gastric ulceration}

Ulcer score was significantly $(\mathrm{p}<0.05)$ higher in Dex group than control. Treatment with taxifolin significantly $(\mathrm{p}<0.05)$ reduced ulcer score. Dexamethasone alone lowered gastic ulceration as shown in figure 5

\section{Ulcer index}

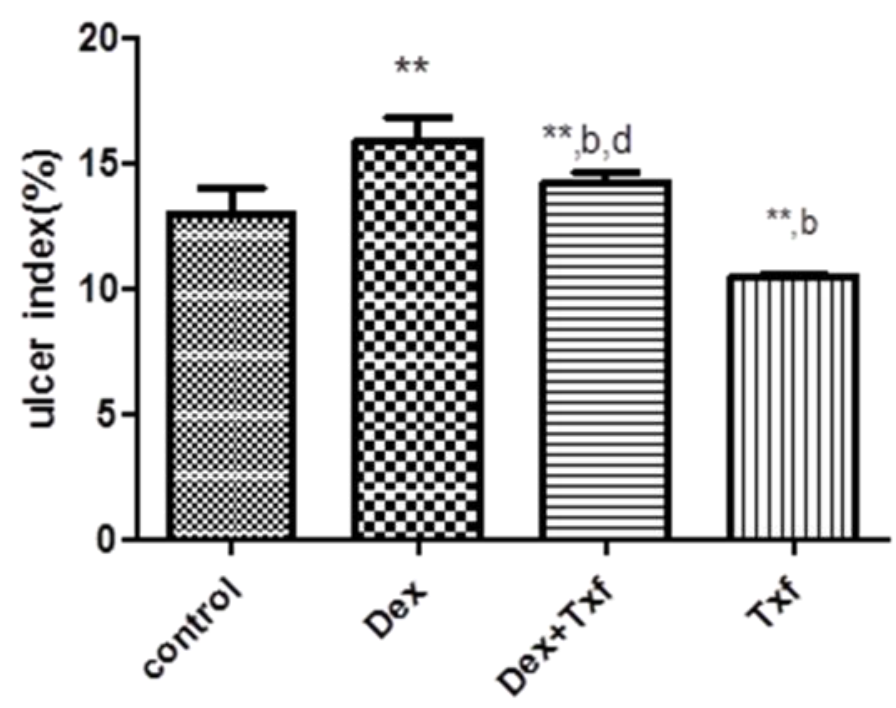

Figure 5 Showing effect of dexamethasone ( $3 \mathrm{mg} / \mathrm{kg}$ ) treatment and taxifolin (Dihydroquercetin - $1 \mathrm{mg} / \mathrm{kg}$ ) supplementation on gastric acid secretion. Values are expressed in Mean \pm SEM; $n=5 . * *=p<0.05$ vs control; $b=p<0.05$ vs Dex; $\mathrm{c}=\mathrm{p}<0.05$ vs TXF 


\section{Discussion}

The use and benefit of dexamethasone as a proinflammatory and as an anti-inflammatory drug has over the time been controversial. To some, it serves a gastroprotective function and has the ability to maintain blood flow, mucus secretion and gastric mucosal integrity [16] while to others it is said to be detrimental to both the cardiovascular system and the gastrointestinal tract. To this end, we examined the effect of taxifolin (dihydroquercetin) supplementation on prostaglandin and thromboxane - A2 (THX-A2) on gastric acid secretion in dexamethasone treated rats. Our results showed that dexamethasone, a synthetic glucocorticoid, potentiates gastric acid secretion and gastric mucosal excoriation. Previous experimental reports have demonstrated that dexamethasone treatment may stimulate gastric acid secretion $[17,18,19]$ by inhibition of prostaglandin synthase and peroxidase enzyme, thereby inhibiting the biosynthesis of prostaglandin[20]; by blunting the $\mathrm{H}+\mathrm{K} 2+$ ATPase inhibitor and suppressing epithelial cell proliferation via inhibition of cyclooxygenase $-2(\mathrm{Cox}-2)$ and reduced mucosal wall regeneration [21]. One mode of action of glucocorticoid is its regulation of gene expression through glucocorticoid receptors that are mostly found in the parietal cells [22]. Interestingly, our result showed that increase in gastric acid secretion caused by dexamethasone may not be histaminergic.

We also demonstrated that treatment with dexamethasone caused a significant decrease in prostaglandin E2 concentration and a raised level of thromboxane A2. Clinical trials have proven that endogenous prostaglandins may modulate gastric acid secretion via inhibition of histamine - stimulated cAMP formation and improved mucus and bicarbonate secretion [12].

The high level of thromboxane A2 (THX -A2) derived probably from Cox-1in a series of metabolic reaction involving thromboxane A2 synthase, observed in this study, may have been responsible for the gastric ulceration, prevention of mucosal epithelial proliferation and delayed healing [23]. THX- A2 affects vasoconstriction and endothelial adhesion molecule expression $[24,25]$. There was however no pathology identified in all groups.

Supplementation of dexamethasone with taxifolin yielded a better gastroprotection and reduced both gastric acid secretion and thromboxane A2 level but upregulated PGE2 and mucus secretion.

Taxifolin is an effective polyphenolic compound and a food and nutritional supplement with gastroprotective ability against a variety of ulcerogenic agents [26]. This compound scavenges free radicals because of its conjugation structures and protects the gastrointestinal mucosa lesions produced by various experimental ulcer models and against different necrotic agent [27]. Being a flavanoid, a shows an outstanding propensity to exhibit efficacy and anti-ulcerogenic activity via precipitation of microproteins on ulcerated areas thereby forming a barrier to easy penetration on the surface of the mucosal lining thus inhibiting easy uptake of substances that may be damaging and also preventing degradation by proteolytic enzymes $[28,29,30$. It also inhibited basal histamine induced secretion as well as augmented cimetidine (H2receptor blocker) inhibitory activity. These results indicates that with its flavonoid property, taxifolin may be acting via inhibition of the H2-receptors.

Other earlier possible mechanisms proposed have been scavenging of free radicals, inhibition of inward flow of calcium ions, modulation of mucosal membrane permeability and promoting mucus secretion. Mucus in the gastric mucosa offers protection against excoriation of the mucosal lining [31] by the corrosive activity of the acid available in the stomach. In this study, taxifolin elicited increased mucus secretion which forms a gel layer that serves as a primary barrier against acid induced excoriation

\section{Conclusion}

Taxifolin decreases dexamethasone-induced gastric acid secretion, increases prostaglandin activity but reduces serum thromboxane A2 concentration.

\section{Compliance with ethical standards}

\section{Acknowledgments}

Sincere thanks to Dr. Okwari Obem, of the Department of Physiology, Cross River University of Technology, Calabar for his technical assistance towards the completion of this research work. 


\section{Disclosure of conflict of interest}

The author declare that there is no conflict of interests regarding the publication of this paper.

\section{Statement of ethical approval}

Ethical approval for the study using experimental animals was obtained from the Faculty of Basic Medical Science Animal Research Ethical Committee of Cross River University of Technology, Calabar, Nigeria (approval number FBMS/CRUTECH/18/020)..

\section{References}

[1] Olsen M, Christensen S, Riis A, Thomsen RW. Preadmission use of systemic glucocorticoids and 30-day mortality following bleeding peptic ulcer: A population-based cohort study. Am J Ther. 2010; 17: 23-29.

[2] Luo JC, Chang FY, Chen TS, Ng YY, Lin HC, Lu CL, et al. Gastric mucosal injury in systemic lupus erythematosus patients receiving pulse methylprednisolone therapy. Br J Clin Pharmacol. 2009; 68: 252-259.

[3] Ludmila filaretova. Glucocorticoids are Gastroprotective under Physiologic Conditions. Ther Adv Chronic Dis. 2011; 2(5): 333-342.

[4] Zhang Y, Croft KD, Mori TA, Schyvens CG, McKenzie KU, Whitworth JA. The antioxidant tempol prevents and partially reverses dexamethasone-induced hypertension in the rat. Am J Hypertens. 2004; 17: 260-265.

[5] Safaeian L, Zabolian H. Antioxidant effects of bovine lactoferrin on dexamethasone-induced hypertension in rat. ISRN Pharmacol. 2014;

[6] Filaretova LP, Maltcev AN, Bogdanov AI, Levkovich YuI. Role of gastric microcirculation in the gastroprotection by glucocorticoids released during water-restraint stress in rats. Chin J Physiol. 1999; 42: 145-152.

[7] McCafferty DM, Granger DN, Wallace JL. Indomethacin-induced gastric injury and leukocyte adherence in arthritic versus healthy rats. Gastroenterology. 1995; 109: 1173-1180.

[8] Derelanko MJ, Long JF. Influence of prednisolone on ethanol-induced gastric injury in the rat. Dig Dis Sci. 1982; 27: $149-154$.

[9] Suzuki M, Mori M, Miura S, Suematsu M, Fukumura D, Kimura H, et al. Omeprazole attenuates oxygen derived free radical production from human neutrophils. Free Rad Biol Med. 1996; 21: 727-31.

[10] Takeuchi K, Nishiwaki H, Okada M, Niida H, Okabe S. Bilateral adrenalectomy worsens gastric mucosal lesions induced by indomethacin in the rat. Role of enhanced gastric motility. Gastroenterology. 1989; 97: 284-293.

[11] Uday, Kausik Biswas, Debashis Bandyopadhyay, Chayan Ganguly, Ranajit Banerjee. Dexamethasone makes the gastric mucosa susceptible to ulceration by inhibiting prostaglandin synthetase and peroxidase - two important gastroprotective enzymes. Molecular and Cellular Biochemistry. 1999; 202: 31-36.

[12] Cohen MM. Role of endogenous prostaglandins in gastric secretion and mucosal defense. Clin Invest Med. 1987; 10(3): 226-31.

[13] Gosh MN, Schild HO. Br. J.Phaarmacology. 1958; 13: 54-61.

[14] Osim EE, Nneli RO, Etem SE, Etta KM. Nigeria Journal of Physiological Sciences. 1991; 7(1): 22-28.

[15] Ibu JO, Iyama AC, Ijiye CT, Ishmael D, Nwokeduiko S. Effect of cola accuminata and cola nitida on gastric acid secretion. Proc. West afri. Soc.Gastroenterol 1986; 1: 5-6.

[16] Filaretova LP, Podvigina TT, Bagaeva TR, Tanaka A, Takeuchi K. Mechanisms underlying gastroprotective action of glucocorticoids released in response to ulcerogenic stress factors. Ann NY Acad Sci. 2004; 1018: 288-293.

[17] Lang PA, Schniepp R, Kirchhoff P, Socrates T, Sidani SM, Geibel JP. PI3 kinase dependent stimulation of gastric acid secretion by dexamethasone. Cellular physiology and biochemistry. 2007; 20: 527-534.

[18] Gray SJ, Benson JA, Reifenstein RW. Chronic stress and peptic ulcer.effect of corticotropin(ACTH) and cortisone on gastric secretion. J. AM med. Assoc. 1951; 147: 1529-1537.

[19] Haikonen M, Rasanen T. Hydrogen ion concentration in gastric juice after pylorus ligationin dex treated rats. 1965; 65: 378-382. 
[20] Miller TA. Protective effects of prostaglandins against gastric mucosal damage: current knowledge and proposed mechanism. Am. J Physiol. 1983; 245: G601-G623.

[21] Luo JC, Shin VY, Liu ES, Ye YN, Wu WK, So WH, et alDexamethasone delays ulcer healing by inhibition of angiogenesis in rat stomachs. Eur J Pharmacol. 2004; 485: 275-281.

[22] Kanemasa H, Ozawa H, Konishi H, Ito T, Nishi M, Mitsufuji S, et al. Distribution of glucocorticoid receptor immunoreactivity in gastric mucosa of normal and adrenalectomized rats. Dig Dis Sci. 1999; 44: 2081-2087.

[23] Takahashi S, Shigeta J, Ishikawa M, Kobayashi N, Okabe S. Role of thromboxane A2 in healing of gastric ulcers in rats. Jpn J Pharmacol. 1999; 79(1): 101-7.

[24] Ding X, Murray PA. Cellular mechanisms of thromboxane A2-mediated contraction in pulmonary veins. Am. J. Physiol. Lung Cell. Mol. Physiol. 2005; 289: L825-L833.

[25] Yamamoto K, Ebina S, Nakanishi H, et al. Thromboxane A2 receptor-mediated signal transduction in rabbit aortic smooth muscle cells. Gen. Pharmacol. 1995; 26: 1489-1498.

[26] Parmar NS, Ghosh MN. Gastric anti-ulcer activity of (+)-cyanidanol-3, a histidine decarboxylase inhibitor. Eur. J. Pharmacol. 1981; 69: 25-32.

[27] Kelly Samara de Lira Mota, Guilherme Eduardo Nunes Dias , Meri Emili Ferreira Pinto , Ânderson Luiz-Ferreira , Alba Regina Monteiro Souza-Brito , Clélia Akiko Hiruma-Lima José Maria Barbosa-Filho and Leônia Maria Batista Flavonoids with Gastroprotective Activity.ISSN 1420-3049Molecules. 2009; 14: 979-1012.

[28] Borrelli F, Izzo AA. The Plant kingdom as a source of Anti- ulcer remedies. Phytother. Res. 2001; 53: 82-8.

[29] Suja PR, Anuradha CV, Viswanathan P. Gastroprotective effect of fenugreek seeds (Trigonella foenum graecum) on experimental gastric ulcer in rats. J. Ethnopharmacol. 2002; 8: 393-397.

[30] Sabiha S, Mohd AA, Asif M, Aktar M. Roles of phenolic compounds in peptic ulcer: an overview. Journal of Pharmaceutical Biollied Science. 2011; 3(3): 361-367.

[31] Maity B, Chattopadhyay S. Natural antiulcerogenic agents: an overview. Current Bioactive Compounds. 2008; 4: 225-24. 